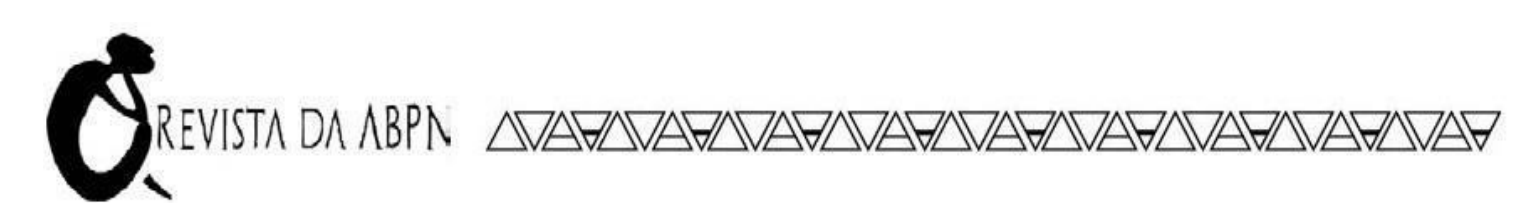

DOI 10.31418/2177-2770.2019.v11.c2.p73-86| ISSN 2177-2770

Licenciado sob uma Licença Creative Commons

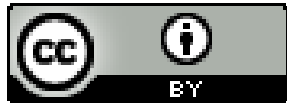

\title{
O BATUQUE DE UMIBIGADA DO INTERIOR DE SÃO PAULO: TRADIÇÃO ORAL, MEMÓRIA E ANCESTRALIDADE
}

\section{Claudete Sousa Nogueiral}

Resumo: $O$ artigo tem por objetivo apresentar um histórico do universo em que se insere atualmente o batuque de umbigada, também conhecido como Caiumba ou Tambú, como uma tradição cultural de grupos negros no interior paulista. As reflexões fazem parte de uma pesquisa desenvolvida no Doutorado que buscou compreender essa tradição ancestral, a partir da memória e da narrativa oral de homens e mulheres, que se consideram herdeiros dessa tradição.

Palavras Chave: Tradição Oral; Memória; Resistência Cultural.

\section{THE UMBIGADA DRUMMING OF SÃO PAULO COUNTRYSIDE: ORAL TRADITION, MEMORY AND ANCESTRY}

\begin{abstract}
The article aims to present an history of the universe in which Caiumba is currently inserted, also known as batuque de umbigada or tambú, as a cultural tradition of black groups in the interior of São Paulo, trying to highlight the role of Memory and Orality in this process. The reflections are part of a research developed at the Doctorate level that sought to understand this ancestral tradition, from the memory and oral narrative of men and women, who consider themselves heirs of this tradition.
\end{abstract}

Keywords: Oral Tradition; Memory; Cultural Resistance.

\section{BATTERIE UMIBIGATED À L'INTÉRIEUR DE SÃO PAULO: TRADITION ORALE, MÉMOIRE ET ASCENDANCE}

Résumé: L'objectif de cet article est de présenter une histoire de l'univers dans laquelle la batuque de umbigada, également connue sous le nom de Caiumba ou Tambú, s'insère actuellement dans la tradition culturelle des groupes noirs à l'intérieur de São Paulo. Les réflexions font partie d'une recherche développée au niveau du doctorat qui cherchait à comprendre cette tradition ancestrale,

\footnotetext{
${ }^{1}$ Possui graduação em História pela Universidade de Sorocaba- UNISO (1990), Mestrado em História pela Universidade Estadual Paulista Júlio de Mesquita Filho - UNESP (1998) e Doutorado em Educação pela Universidade Estadual de Campinas - UNICAMP (2009). Atualmente é docente assistente Doutora da Universidade Estadual Paulista Júlio de Mesquita Filho (UNESP). É Vice Coordenadora executiva do Núcleo Negro da Unesp para pesquisa e extensão (NUPE); Coordenadora do Grupo de pesquisa Educação das relações étnico-raciais (ERE) vinculado ao Núcleo Negro da UNESP para Pesquisa e Extensão (NUPE). E-mail: claudete.nogueira@unesp.br
}

Revista da ABPN • v. 11, Ed. Especial - Caderno Temático: Cultura popular em cena: artes afro diaspóricas $\bullet$ julho de 2019, p. 73-86 
à partir de la mémoire et du récit oral d'hommes et de femmes, qui se considèrent comme les héritiers de cette tradition.

Mots-clés: tradition orale; La mémoire; Résistance culturelle

\title{
EL TAMBORILEO DE UMBIGADA EN EL CAMPO DE SÃO PAULO: TRADICIÓN \\ ORAL, MEMORIA Y ASCENDENCIA
}

Resumen: El artículo tiene por objetivo presentar un histórico del universo en que se inserta actualmente el batuque de umbigada, también conocido como Caiumba o Tambú, como una tradición cultural de grupos negros en el interior paulista. Las reflexiones forman parte de una investigación desarrollada a nivel de Doctorado que buscó comprender esa tradición ancestral, a partir de la memoria y de la narrativa oral de hombres y mujeres, que se consideran herederos de esa tradición.

Palabras Clave: Tradición Oral; Memoria; Resistencia Cultural.

\section{INTRODUÇÃO}

\begin{abstract}
"Depois das imagens do rio Tietê, seus pássaros, a vegetação à margem, as águas calmas ou encachoeiradas, surge a fogueira que aquece o couro e afina o tambor, as mãos que experimentam o som, os outros sons do início de uma festa ancestral que corre o risco de acabar..." (Jornal O Estado de São Paulo. 05/10/2003. p. D14)
\end{abstract}

Essas palavras, publicadas no jornal O Estado de São Paul em 2003, faziam referência a uma manifestação cultural encontrada no interior do Estado de São Paulo, trazida para o Brasil pelos povos africanos de origem bantu, denominada tambu ou caiumba. Essa tradição cultural é uma dança, da qual participam homens e mulheres, que tem como característica a umbigada no final da coreografia, dançada ao toque do tambu, uma espécie de tambor feito de tronco oco de árvore.

Definição parecida chega o Professor Roger Bastide em 1943, quando acompanhado por seus alunos do Curso de Sociologia da Faculdade de Filosofia, Ciências e Letras da Universidade de São Paulo, desenvolveu uma experiência de campo em Tietê, onde se realizava o batuque de umbigada em comemoração ao Treze de Maio. Dos trabalhos que resultaram dessa pesquisa, destacam-se a Tese de Doutorado intitulada “Algumas danças populares no Estado de São Paulo”, desenvolvida por Lavínia Raymond

Revista da ABPN • v. 11, Ed. Especial - Caderno Temático: Cultura popular em cena: artes afro diaspóricas • julho de 2019, p. 73-86 
$(1954)^{2}$, e um artigo intitulado “Opiniões e Classes Sociais em Tietê", escrito por Antônio Candido, em $1947^{3}$. Mesmo distanciados pelo tempo, os autores dos referidos trabalhos chegam a pareceres semelhantes sobre as transformações e a duração dessa tradição cultural no interior paulista: ambos chegam à conclusão de que o batuque estava prestes a acabar.

No entanto, quem passa pelas cidades de Piracicaba, Capivari e Tietê atualmente, pode ouvir os sons do tambu e, ao mesmo tempo, presenciar a dança entre homens e mulheres, que organizados em fileiras se defrontam, encontram-se no centro do salão fazendo passos variados e terminam com a umbigada, contrariando, dessa forma, a previsão dos pesquisadores na década de 1940 e do jornalista no início do século XXI, uma vez que essa tradição cultural negra do interior paulista, continua presente.

Para compreender melhor o contexto no qual a dança está inserida, é valido pensar: quem são os sujeitos envolvidos nesse processo de resistência e transformação cultural? De que maneira a memória e a oralidade se constituem como elementos bases para a manutenção dessa tradição ancestral? São questões relevantes para quem busca entender a cultura popular a partir das transformações da sociedade contemporânea. Compartilhamos com as conclusões de Ayala \& Ayala (2003), quando se referem às práticas culturais populares de "que, ao contrário do que afirmam muitos estudiosos que acreditam em seu desaparecimento, na verdade, se modificam, juntamente com o contexto social em que estão inseridas, sem que isso implique necessariamente sua extinção.” (Ayala \& Ayala, 2003, p.20).

Segundo Hall (2003), a cultura popular, como todas as coisas feitas pelo povo, ou seja, as experiências, memórias e tradições, se configuram em território composto de elementos antagônicos e instáveis, vinculados à aspectos relacionados ao contexto social. É nesta perspectiva que compreendemos as tradições culturais afro-brasileiras, como a

\footnotetext{
${ }^{2}$ A autora desenvolve uma pesquisa etnográfica na qual descreve danças como o Batuque de Umbigada, Moçambique, Jongo e Congado.

${ }^{3}$ Nesse artigo, Antônio Candido analisa a reação da população de Tietê frente ao batuque feito pelos negros. O autor chega à conclusão de que a opinião da população de Tietê em relação ao batuque estava estreitamente ligada à classe social dos indivíduos.
}

Revista da ABPN • v. 11, Ed. Especial - Caderno Temático: Cultura popular em cena: artes afro diaspóricas $\bullet$ julho de 2019, p. 73-86 
Caiumba, o Jongo, a Capoeira, entre outras, que vêm se transformando com o tempo, ocupando outros espaços e demonstrando sua capacidade de resistência.

Ao considerar esse contexto, o presente artigo tem como objetivo apresentar um histórico do universo em que se insere atualmente o batuque de umbigada, também conhecida como Caiumba ou Tambú, como uma tradição cultural de grupos negros no interior paulista. As reflexões fazem parte de uma pesquisa desenvolvida no Doutorado que buscou compreender essa tradição ancestral, a partir da memória e da narrativa oral de homens e mulheres, que se consideram herdeiros dessa tradição.

\section{MEMÓRIA, TRADIÇÃO E ORALIDADE}

Contam os africanos que, em Wuidá, onde ficava um dos grandes portos de embarque de escravos, na África, os negros percorriam um caminho de cinco quilômetros da cidade até o porto. Neste percurso, todo escravo que ia embarcar era obrigado a dar voltas em torno de uma árvore, a chamada árvore do esquecimento. Os escravos homens deveriam dar nove voltas em torno dela e, as mulheres, sete voltas. Depois disso, supunhase que os escravos perdiam a memória e esqueciam completamente seu passado, suas origens e sua identidade cultural, para se tornarem seres sem nenhuma vontade de reagir ou de se rebelar. ${ }^{4}$

O tráfico Atlântico ou "a travessia da Calunga Grande", que ocorreu entre os séculos XV e XIX, é considerada a maior experiência de diáspora compulsória de seres humanos, envolvendo o tráfico de cerca de 15 milhões de homens, mulheres e crianças africanas, arrancados de suas terras e transportados para as Américas e para a Europa.

Arrancados de seu continente, os africanos foram tratados como mercadoria, coisa,

\footnotetext{
4 Depoimento transcrito do documentário "Atlântico Negro- na rota dos Orixás”. Áudio visual sob direção de Renato Barbieri. 1998.54min

5 O termo "calunga" já existia entre os negros africanos antes do processo de escravização. Calunga Grande era o perigoso e misterioso Oceano Atlântico.
}

Revista da ABPN • v. 11, Ed. Especial - Caderno Temático: Cultura popular em cena: artes afro diaspóricas $\bullet$ julho de 2019, p. 73-86 
peça, objetos: eles não eram considerados humanos. Mas, ao contrário do que se acreditou durante muito tempo, em momento algum, transformaram-se em objetos. Esses grupos negros, mesmo escravizados, contribuíram de maneira significativa na formação social das regiões onde se fixaram, ora por meio da reafirmação de sua cultura ora pela construção do seu processo de identidade.

Apesar de existir historicamente a tentativa de se criar um processo de esquecimento, a memória se constituiu como um importante elemento de preservação de conhecimentos e valores do povo negro. A exemplo do depoimento registrado pelo documentário "Atlântico Negro: na Rota dos Orixás", em que um dos descendentes desses escravos de Wuidá desabafa: "Que aberração! Que contradição! Na história humana alguém já viu um nagô esquecer suas origens? Sua identidade cultural? Se ela está tão marcada em seu rosto e tão incrustada em seu coração?"

Assim, fica evidente que contradições e sofrimentos vividos pela população negra nas Américas não foram suficientes para exterminar uma cultura que aqui se enraizou e tornou-se símbolo de resistência. As histórias desses deslocamentos e identidades caracterizam o que Gilroy (2001) define como Atlântico Negro, isto é, um conjunto cultural irredutivelmente moderno, excêntrico, instável e assimétrico. Nesse caso, a identidade negra é abordada pelo autor como uma construção política e histórica marcada pelas trocas culturais através do Atlântico com suas experiências de desenraizamento, deslocamentos e criação cultural. Essas experiências se produziram desde o tráfico negreiro, um trauma original, até as mais diversas experiências de encantamento e estranhamento feitos em viagens e exílios entre América, Europa e África.

Gilroy (2001) ressalta a importância de se compreender esse fenômeno não como uma forma simples de dispersão catastrófica do negro, mas como um processo que redefine a mecânica cultural e histórica do pertencimento. Sob a idéia-chave da diáspora, nós poderemos então ver "as formas geopolíticas e geoculturais de vida que são resultantes da interação entre sistemas comunicativos e contextos que elas não só incorporam, mas também modificam e transcendem" (Gilroy, 2001, p.25). O autor propõe uma maneira transnacional de refletir sobre a experiência negra no mundo, destacando o

Revista da ABPN • v. 11, Ed. Especial - Caderno Temático: Cultura popular em cena: artes afro diaspóricas $\bullet$ julho de 2019, p. 73-86 


\section{Otmanm}

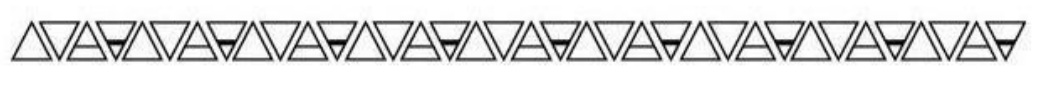

intenso intercâmbio entre as comunidades negras, dos dois lados do Atlântico, entre os séculos XVIII e XIX. Essas relações estabelecidas pela diáspora possibilitaram a formação de um circuito comunicativo que extrapola as fronteiras étnicas do EstadoNação, permitindo às populações dispersas conversar, interagir e efetuar trocas culturais. No entanto, isso envolve a difícil tarefa de:

"tentar compreender a reprodução das tradições culturais, não na transmissão tranquila de uma essência fixa ao longo do tempo, mas nas rupturas e interrupções que sugerem que a invocação da tradição pode ser, em si mesma, uma resposta distinta, porém oculta, ao fluxo desestabilizante do mundo contemporâneo." (Gilroy, 2001.p. 208).

Assim, compreender a história do Atlântico Negro, isto é, a diáspora dos negros africanos, é compreender as instabilidades e transformações das identidades com suas características dinâmicas, que estão sempre sendo refeitas. (Gilroy, 2001).

$\mathrm{O}$ batuque de umbigada se insere nesse universo cultural trazido pelos africanos e que, aos poucos, foi se ressignificando a medida em que se espalhou nos diferentes espaços, transformando-se em uma cultura heterogênea com seus instrumentos como o Tambu, uma espécie de tambor feito, como dito, de tronco oco de árvore; Quinzengue, um tambor mais agudo que faz a marcação rítmica do Tambu e nele se apoia; as Matracas, que são os paus que batem no Tambu do lado oposto do couro; Guaiás ou Chocalhos de metal em forma de cones ligados, atravessou o tempo, passando de geração para geração. $\mathrm{Na}$ característica da dança, homens e mulheres formam duas filleiras que se defrontam e quase encontram no centro do salão, fazendo passos variados e terminam com a umbigada. Atualmente as cidades de Tietê, Capivari e Piracicaba, no interior de São Paulo, continuam sendo espaços dessas manifestações.

O Treze de Maio em Piracicaba, o Sábado de Aleluia em Capivari e a Festa de São Benedito em Tietê são algumas das ocasiões em que passado e presente se confundem na dança de umbigada, nos reaquecimentos dos tambores ao calor da fogueira, nos longos versos improvisados em que homens e mulheres, jovens e velhos (re)vivem um ritual que o tempo não conseguiu apagar.

Revista da ABPN • v. 11, Ed. Especial - Caderno Temático: Cultura popular em cena: artes afro diaspóricas $\bullet$ julho de 2019, p. 73-86 


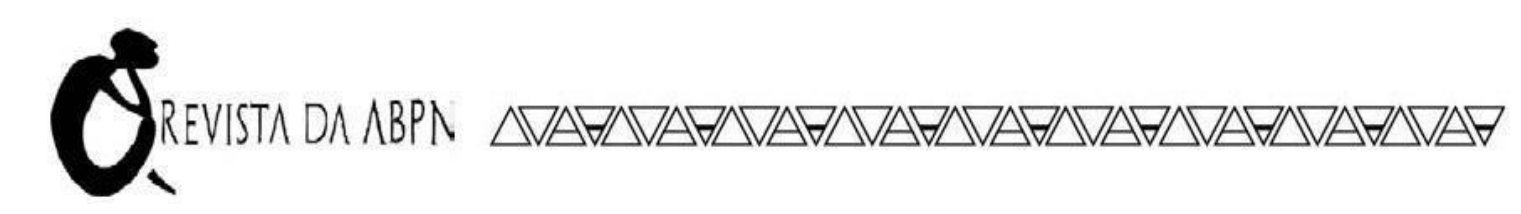

A tradição do batuque pode ser entendida como uma síntese de elementos das tradições e memórias africanas e outras formas de expressão e sistemas simbólicos com que os negros da diáspora se confrontaram no Novo Mundo. Azevedo (2014) destaca em sua pesquisa sobre o universo do músico Geraldo Filme a respeito dos bairros que estabeleceu relações, a sua contribuição para consolidar cartografias e memórias de uma modalidade de samba com traços da diáspora africana em São Paulo.

...não é automática e nem mecânica. O que percebi na experiência social de Geraldo Filme e suas músicas foram sinais dessa conexão que se manifestaram como traços de uma memória africana que fora acessada e recomposta entre os negros através dos saberes orais acústicos em torno das relações de família, amizade, trabalho e música, salões de dança, cordões carnavalescos, escolas de samba, festas e religiosidades. (Azevedo, 2014, p. 317)

Portanto, os significados culturais de origens africanas foram reinventados e transformados pelos escravizados e seus descendentes, gerando um processo híbrido que caracterizou as manifestações afro-brasileiras.

\section{AS NARRATIVAS DOS BATUQUEIROS SOBRE O BATUQUE DE UMBIGADA}

$\mathrm{Na}$ coleta de narrativas orais, nas observações e conversas informais que tivemos com os batuqueiros e batuqueiras, buscamos reconstituir a partir da memória, a história e o sentido que existe dessa tradição ancestral. Para conduzir a coleta de depoimentos, formulamos algumas questões com o objetivo de perceber o significado da África, da escravidão e da resistência cultural na perspectiva daqueles que se identificam como herdeiros da tradição do batuque.

Seu Pedro Soledade, morador do Sítio Pau d'Alhinho, narra com orgulho, seu vínculo com os ancestrais batuqueiros:

Revista da ABPN • v. 11, Ed. Especial - Caderno Temático: Cultura popular em cena: artes afro diaspóricas • julho de 2019, p. 73-86 


\section{OH}

Eram escravos. Depois a sinhá deu o terreno pros escravos daqui, eram parentes nossos. Então foi ficando, que tem essa raiz até hoje que nós ficamos aqui. $\mathrm{Na}$ época, já tinha batuque. Então o batuque, de Tambu mesmo daqui, o nosso, já faz mais de 100 anos. Então aí foi continuando fazendo, aí morreram os mais velhos, foi ficando nós, foi fazendo, fazendo e a gente continua até hoje (...). De quando sempre todo ano, a gente procura fazer, pra continuar. (Depoimento concedido a autora em 28/01/2006)

Percebe-se, na memória desses batuqueiros, que a África ancestral se torna elemento essencial no processo de identificação e de reconhecimento coletivo da legitimidade na tradição. Ao enfatizarem a ancestralidade, eles reconhecem a força e os saberes dos falecidos e dos mais velhos no tempo presente.

As rememorações refletem também a necessidade de se ressaltar a resistência ao sofrimento do cativeiro, como uma das narrativas de um neto de escravizado da cidade de Piracicaba:

Essa dança nossa aqui é caiumba. Nêgo dançava no mato. Escravo dançava no mato. Furava esse pau aí com fogo, que ocê tá veno aí, furava com fogo, escondido de sinhô. Africano, no mato, furava esse pau com fogo. Pá podê diverti, escondido de sinhô. Naquele tempo que existia escravidão. ${ }^{6}$

Essa herança é também motivo de orgulho e reafirmação da legitimidade de pertencimento a uma tradição, como canta o batuqueiro Bomba de Tietê:

Todo mundo já conhece, eu sou o Bomba de Tietê, Eu sou nascido na Caiumba e na Caiumba eu vou morrer! ${ }^{7}$

Desse modo, as narrativas dos batuqueiros e batuqueiras trazem o sentido da ligação com esse legado cultural que, mesmo que ressignificado e transformado no decorrer do tempo, é referência para o indivíduo e para o grupo. Ao reconstruírem suas histórias de vida, acabam reconstruindo também a história do grupo familiar, misturando,

\footnotetext{
${ }^{6}$ Theotônio de Moura, do Batuque de Piracicaba, SP. In: Documentos sonoros Brasileiros. Acervo Cachuera. ${ }^{7}$ Bomba, Batuqueiro de Tietê, SP; In: "No repique do tambú.-O Samba de Umbigada Paulista" (2003) Direção: Paulo Dias e Rubens Xavier. Realização: Associação Cultural Cachuera! Co-produção: TV Cultura e Rede Sesc-Senac dTV. vhs - ntsc $56 \mathrm{~min}$.
}

Revista da ABPN • v. 11, Ed. Especial - Caderno Temático: Cultura popular em cena: artes afro diaspóricas $\bullet$ julho de 2019, p. 73-86 
muitas vezes, lembranças suas e de seu grupo. Essa reconstrução é fundamental para que se estabeleça a identidade atual na família, destacando-se, o orgulho e a percepção de responsabilidade pelo fato de ser "herdeiro" dos bens e da tradição deixada pelos antepassados.

As lembranças dos narradores também acentuam a necessidade de se compreender o sentido da dança, buscando relações com seu cotidiano. Para Antonio Filogênio Júnior, batuqueiro de Piracicaba, o significado da umbigada, de suas origens, está além de um ritual profano:

O umbigo seria o primeiro canal de alimentação quando nós estamos no ventre materno, mas também é um canal onde nós recebemos energia e quando se toca o umbigo de homem e mulher é como se essas energias pudessem ser ampliadas, que ajudassem a reorganizar o próprio universo. Então é uma coisa muito mais ampla. (Depoimento concedido a autora em 02/12/2005)

A coleta e análise das narrativas orais permitiu concluir que a relação do batuque de umbigada com a ancestralidade africana tornou-se, para o grupo, uma cultura de resistência, capaz de influenciar a maneira de se posicionar perante os novos contextos. Nesse caso, as exigências e necessidades do presente vão direcionando a reconstrução do passado. (Halbwachs, 1990). Entende-se que, a dança do Caiumba se insere nas sociedades de memória, na medida em que a memória é organizada e retida pelo conjunto de seus membros, que tem a função de transmiti-la às novas gerações, cabendo aos mais velhos, com sua maior experiência e vivência, o importante papel social de guardiões da memória.

\section{A TRANSMISSÃO DE CONHECIMENTOS NA TRADIÇÃO ORAL: OS MESTRES}

As tradições orais na África representam espaços simbólicos de preservação de dados históricos e, também, da interpretação destes mesmos dados. Mais do que fontes informativas sobre história de povos africanos, as tradições orais revelam muito da

Revista da ABPN • v. 11, Ed. Especial - Caderno Temático: Cultura popular em cena: artes afro diaspóricas $\bullet$ julho de 2019, p. 73-86 
relação dos seus autores com o conhecimento histórico (Amadou Hampate-Bâ, 1973). Assim como na África, a palavra é entendida como memória viva, uma vez que podemos perceber que a oralidade se tornou fundamental no processo de aprendizagem que envolve a cultura negra no Brasil.

No batuque de umbigada, os mestres, ou seja, os homens mais velhos, dispõem de autoridade perante o grupo, tendo o papel de transmitir os saberes dos antepassados por meio da oralidade e da dança. A figura dos mestres ganha uma função fundamental no processo de resistência e identidade, pois eles representam o elo vivo entre gerações e, como mediadores, transmitem a história de um passado vivido e experimentado.

A imagem dos mestres é referência fundamental para os grupos familiares de batuqueiros e batuqueiras de Piracicaba, Capivari e Tietê na reconstrução do passado. Dificilmente há um questionamento de sua autoridade, sendo também considerados líderes responsáveis por manter a estabilidade do grupo, controlar os conflitos e administrar os bens simbólicos da tradição.

Nas narrativas desses batuqueiros e batuqueiras, a reconstituição da vida dos mestres está geralmente ligada à memória familiar, em que tios, avós, padrinhos são citados como referência significativa na vida individual e coletiva. Júnior, batuqueiro de Piracicaba, narra, emocionado, o significado dessa aprendizagem para o grupo:

Nisso também se formavam escolas. Então, existiam escolas desses grandes mestres, por exemplo, a escola da família Caxias, a escola da família Toledo; eram escolas, e como era uma tradição que se aprende de boca de Mestre com ouvido de aprendiz, como diz o Mestre Lumumbo, aí, você pegava a influência muito daquele que te ensinava do jeito dele tocar, então as dobras, os improvisos, o jeito de cantar, a forma de construir o verso. Então, se pegava muito essa influência (...) tinha muito das características (...)”. (Júnior. Depoimento concedido a autora em 02/12/2005).

E ao reconstituir um pouco da história do Rei Domingos, mestre da Caiumba em Tietê, ele demonstra como influenciou muitas das gerações de batuqueiros:

Revista da ABPN • v. 11, Ed. Especial - Caderno Temático: Cultura popular em cena: artes afro diaspóricas $\bullet$ julho de 2019, p. 73-86 


\section{Otimum}

Ele é chamado de rei Domingos, era da cidade de Tietê e foi uma das pessoas que ensinou o mestre Herculano (...). Inclusive tem um Tambu, no museu de Tietê, que pertenceu ao Rei Domingos. Ele foi muito conhecido não só por ser um grande batuqueiro, mas ele em si era um grande sábio, que ensinava muito, o contador de histórias e que teve uma longevidade, ele morreu bem idoso, morreu bem idoso. Ele passou dos 100 anos, e contou histórias, ensinou muita gente, formou uma legião de batuqueiros. (Depoimento concedido a autora em $02 / 12 / 2005)$.

As narrativas orais destacam aspectos da vida dos mestres como a fonte de transmissão de determinados valores, os quais representam, a seus olhos, uma situação social e, ao mesmo tempo, uma ordem moral. Na fala de Faé, batuqueiro de Piracicaba, fica evidente a admiração e o orgulho de seguir o exemplo do mestre, que ao se referir à história de vida de Tio Tónho, faz as seguintes observações:

O tio Tónho, por exemplo, era um tipo (de mestre) que nem eu estou fazendo hoje. Ele era uma pessoa mais idosa, morador do bairro. Então ele tinha isso. Só que o dele era mais futebol e esse negócio do batuque, ele gostava muito. Então era aquela pessoa que sempre tava ali, quando precisava de instrumento, ele corria atrás, esse negócio de jogo, então quer dizer (...). (Depoimento concedido a autora em 19/01/2006)

As experiências e memórias transmitidas pelos mestres do batuque de umbigada revelam, como destaca Walter Benjamim (1986), uma fonte onde todos se embebedam e onde encontram uma significativa dimensão utilitária. Para o autor, as verdadeiras narrativas:

"têm sempre em si, às vezes de forma latente, uma dimensão utilitária. Essa atitude pode consistir seja num ensinamento moral, seja numa sugestão prática, seja num provérbio ou numa norma de vida. De qualquer maneira, o narrador é um homem que sabe dar conselhos" (Benjamim, 1986. p. 200).

De acordo com Benjamim (1986), um narrador conselheiro é um homem que sabe dar conselho, e que é capaz de tirar dessas narrativas a sabedoria e envolver seus ouvintes, transformando-os em seus companheiros de história. Percebe-se que os mestres

Revista da ABPN • v. 11, Ed. Especial - Caderno Temático: Cultura popular em cena: artes afro diaspóricas $\bullet$ julho de 2019, p. 73-86 


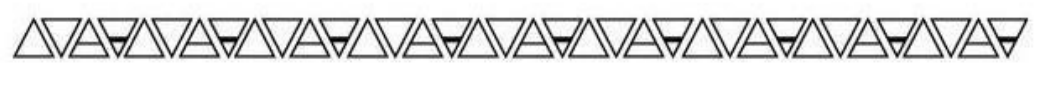

batuqueiros, de uma maneira geral, contribuíram para a organização e a estruturação do grupo. Por meio da oralidade e da transmissão dos saberes acumulados, interferiram não apenas nas práticas e decisões, como também com seus exemplos, modos de vida, maneiras de ser e agir, tornando-se referências para o grupo.

\section{CONSIDERAÇÕES FINAIS}

O presente trabalho teve como objetivo compreender o processo de identificação e de transmissão de saberes a partir de uma prática cultural negra do interior paulista, o batuque de umbigada. Por meio da memória familiar e da oralidade, procurou-se entender as percepções e os sentidos que o grupo construiu para si e para os outros, ou seja, as representações socioculturais produzidas no cotidiano de homens e mulheres.

As narrativas dos batuqueiros e batuqueiras de Piracicaba, Capivari e Tietê revelaram aspectos de uma prática cultural que atravessou gerações, transformada no decorrer dos tempos. Para a maioria dos batuqueiros, participar das festas, dos rituais, dos encontros familiares, vivenciar essa cultura, possibilitou construir valores positivos tanto no âmbito individual como no coletivo. Valores positivos que fizeram a diferença na luta pelo reconhecimento de si e para si, nas novas posturas adotadas que, enfim, deram sentido à vida de cada indivíduo do grupo.

Esse contexto permite ainda destacar outro elemento conclusivo presente na pesquisa no que se refere à cultura afro-brasileira com suas riquezas de saberes, valores e princípios fundamentais para o desenvolvimento do ser humano: ser herdeiro dessa tradição cultural significou, para cada um, afirmar-se como negra e negro e como cidadão, o que se torna muito mais difícil em um espaço de discriminação e de exclusão étnica. Também na construção e (re)construção de identidades em que a memória familiar desempenha um papel importante, pois o fato de pertencer ao grupo trouxe um outro sentido para esses sujeitos. Logo, ser batuqueiro representa conhecer segredos, relembrar informações, dominar aspectos da música e da dança que podem contribuir para a reconstrução da memória que lhe possibilita ser reconhecido por pertencer a uma

Revista da ABPN • v. 11, Ed. Especial - Caderno Temático: Cultura popular em cena: artes afro diaspóricas $\bullet$ julho de 2019, p. 73-86 


\section{Otamaum}

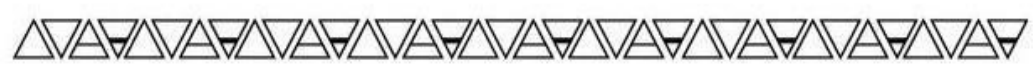

manifestação cultural milenar, o que o faz sentir valorizado socialmente, mesmo que isso não tenha se refletido em suas condições econômicas e sociais em escala mais ampla.

Apropriar-se das informações do passado, dos segredos, dos rituais e ser guardião da memória significou, para os negros e negras-, serem portadores de um conhecimento diferente, que lhes permitem hoje, viver em um espaço marcado pela exclusão e pelo racismo.

\section{BIBLIOGRAFIA}

AYALA, Marcos \&AYALA, Maria Ignez Novais. Cultura Popular no Brasil. São Paulo: 2003.

AZEVEDO, Amailton Magno. São Paulo negra: Geraldo Filme e a geografia do samba paulista. Revista da Associação Brasileira de Pesquisadores/as Negros/as (ABPN), [S.1.], v. 6, n. 13, p. 313-328, jun. $2014 . \quad$ ISSN 2177 2770.Disponível: $<$ http://abpnrevista.org.br/revista/index.php/revistaabpn1/article/view/164>. Acesso em: 08 jun. 2019.

BÂ, Amadou Hampate. "A palavra, memória viva na África" in Correio da UNESCO. Ano 1. $n^{\circ}$ 1, Rio de Janeiro: Fundação Getúlio Vargas, 1973. Amkouell, o menino fula. São Paulo: Palas Athena/Casa das Áfricas, 2003.

CÂNDIDO, Antonio.Opinião e classes em Tietê. Revista Didática e Científica. 1943.

DIAS, Afonso.O batuque em Tietê. Folclore (Orgão da Comissão Paulista de Folclore e do Centro de Pesquisas Folclóricas Mário de Andrade, № 4.1952

DOCUMENTOS sonoros brasileiros. Acervo Cachuera: Batuques do Sudeste[S.1.]: Associação Cachuera, 2001. Itau Cultural

GILROY, Paul. Atlântico Negro: Modernidade e Dupla Consciência. Rio de Janeiro, Editora 34/UCAM - Centro de Estudos Afro-Asiáticos, 2001.

HALL, Stuart. Da Diáspora: Identidades e mediações culturais. Belo Horizonte: UFMG: Representações da UNESCO no Brasil, 2003.

. A identidade cultural na pós-modernidade. Rio de Janeiro: DP\&A, 2001.

Quem precisa de identidade? In: SILVA, T. Tadeu da (Org.). Identidade e diferença: a perspectiva dos estudos culturais. Petrópolis (RJ): Vozes, 2000.

LIMA, Rossini Tavares de. Notas sobre o atual Batuque ou Tambú do Estado de São Paulo: São Paulo, Ricordi, 1954.

Revista da ABPN • v. 11, Ed. Especial - Caderno Temático: Cultura popular em cena: artes afro diaspóricas $\bullet$ julho de 2019, p. 73-86 


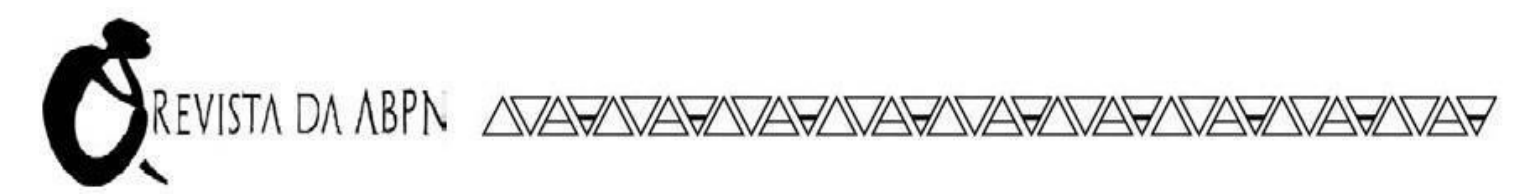

MUKUNA, Kazadi wa. Contribuição bantu na música popular brasileira. São Paulo, Global, 2003.

NO REPIQUE do Tambú - O Samba de Umbigada Paulista (2003) Direção: Paulo Dias e Rubens Xavier. Realização: Associação Cultural Cachuera! Co-produção: TV Cultura e Rede Sesc-Senac dTV. vhs - ntsc 56 min.

RAYMOND, Lavínia Costa. Algumas danças populares no Estado de São Paulo. USP/Faculdade de Filosofia, Ciências e Letras, Boletim nº 191, Sociologia nº 6, São Paulo, 1954.

\section{Fontes Orais}

PAULA JR., Antonio Filogênio. ).[35 anos].[entrevista realizada em dez 2005]. Piracicaba,SP. $02 / 12 / 2005$

SOLEDADE, Pedro. [64 anos].[entrevista realizada em jan 2006]..Piracicaba,SP. 28/01/2006

SOLEDADE,Sebastiana.[90 anos].[entrevista realizada em jan 2006]..Piracicaba,SP. 28/01/2006

Recebido em 30/04/2019

Aprovado em: 30/06/2019

Revista da ABPN • v. 11, Ed. Especial - Caderno Temático: Cultura popular em cena: artes afro diaspóricas $\bullet$ julho de 2019, p. 73-86 